\title{
Incomplete childhood immunization in Nigeria: a multilevel analysis of individual and contextual factors
}

\author{
Sulaimon T. Adedokun ${ }^{1,2^{*}}$, Olalekan A. Uthman ${ }^{1,3}$, Victor T. Adekanmbi ${ }^{4}$ and Charles S. Wiysonge ${ }^{3,5}$
}

\begin{abstract}
Background: Under-five mortality remains high in sub-Saharan Africa despite global decline. One quarter of these deaths are preventable through interventions such as immunization. The aim of this study was to examine the independent effects of individual-, community- and state-level factors on incomplete childhood immunization in Nigeria, which is one of the 10 countries where most of the incompletely immunised children in the world live.

Methods: The study was based on secondary analyses of cross-sectional data from the 2013 Nigeria Demographic and Health Survey (DHS). Multilevel multivariable logistic regression models were applied to the data on 5,754 children aged 12-23 months who were fully immunized or not (level 1), nested within 896 communities (level 2) from 37 states (level 3).

Results: More than three-quarter of the children (76.3\%) were not completely immunized. About $83 \%$ of children of young mothers (15-24 years) and $94 \%$ of those whose mothers are illiterate did not receive full immunization. In the fully adjusted model, the chances of not being fully immunized reduced for children whose mothers attended antenatal clinic (adjusted odds ratio $[\mathrm{aOR}]=0.49 ; 95 \%$ credible interval $[\mathrm{Crl}]=0.39-0.60$ ), delivered in health facility $(\mathrm{aOR}=0.62 ; 95 \% \mathrm{Crl}=0.51-0.74)$ and lived in urban area $(\mathrm{aOR}=0.66 ; 95 \% \mathrm{Crl}=0.50-0.82)$. Children whose mothers had difficulty getting to health facility $(\mathrm{aOR}=1.28 ; 95 \% \mathrm{Crl}=1.02-1.57)$ and lived in socioeconomically disadvantaged communities $(\mathrm{aOR}=2.93 ; 95 \% \mathrm{Crl}=1.60-4.71)$ and states $(\mathrm{aOR}=2.69 ; 955 \mathrm{Crl}=1.37-4.73)$ were more likely to be incompletely immunized.
\end{abstract}

Conclusions: This study has revealed that the risk of children being incompletely immunized in Nigeria was influenced by not only individual factors but also community- and state-level factors. Interventions to improve child immunization uptake should take into consideration these contextual characteristics.

Keywords: Immunization, Children, Incomplete, Multilevel, Factors, Contextual, Model

\section{Background}

Although the world witnessed a tremendous reduction in child mortality between 1990 and 2015, sub-Saharan Africa (SSA) is still characterised by high under-five deaths. As at 2015, under-five mortality (U5MR) in the region was 83 deaths per 1000 live births [1]. One-quarter of these deaths are preventable through interventions such

\footnotetext{
* Correspondence: s.adedokun@warwick.ac.uk; adedokunsulait@gmail.com ${ }^{1}$ Warwick-Centre for Applied Health Research and Delivery (WCAHRD), Division of Health Sciences, University of Warwick Medical School, Coventry, UK

${ }^{2}$ Department of Demography and Social Statistics, Obafemi Awolowo University, lle-Ife, Nigeria

Full list of author information is available at the end of the article
}

as immunization. Reports have indicated that the available vaccines today could prevent an estimated $25 \%$ deaths of children under the age of 5 [2]. It is in view of this that the World Health Organization (WHO) and United Nations Children's Fund (UNICEF) developed the Global Immunization Vision and Strategy with the objectives of increasing the number of children being immunized against preventable diseases, incorporating other interventions with immunization and managing immunization programmes based on global interdependence [3].

This effort was also mirrored in Nigeria as the Expanded Programme on Immunization (EPI) was introduced in the country in 1979. The aim of EPI included 
reduction of vaccine-preventable diseases and improvement of primary health care delivery in different localities. The programme recorded a major success between 1988 and 1990 when diptheria-tetanus-pertussis (DTP) 3 coverage reached $81.5 \%$ [4]. A decline, however, set in around late 1990s, but there have been renewed efforts to revitalize the programme in recent years. Through partnership with international organizations, a comprehensive multi-year strategy was embarked upon to sustainably strengthen the EPI [4]. The strategy aimed at truncating the spread of the poliovirus, introducing new vaccines and improving immunization coverage generally, among others. One of the goals of achieving this aim was to ensure that members of the community were aware of the significance of completing the immunization schedule [4]. In May 2012, Nigeria joined other member states of the World Health Assembly to endorse the Global Vaccine Action Plan; an agenda for universal access to immunisation by 2020 [5].

However, the proportion of children that completed the immunization schedule (that is, those who received BCG against tuberculosis, 3 doses of vaccine against DTP, at least 3 doses of vaccine against polio and 1 dose $\mathrm{f}$ vaccine against measles) is still very low; $30 \%$ in 1990 , $13 \%$ in 2003 and 23\% in 2008 [6-8]. Through previous studies, the low immunization uptake has been attributed to factors such as maternal education, age, occupation, marital status, residence, access to media, fear of side effects, household wealth and place of delivery [9-11]. Most of these studies have concentrated on individual level factors with little attention paid to contextual characteristics. In the present time, emphasis is being placed on the study of social determinants of health in order to have a better understanding of factors influencing people's health. These social determinants transcend individual characteristics. It has been observed that even studies that considered contextual factors have limited their focus on children with complete immunization status [12, 13], leaving out those who did not complete their immunization schedule. Therefore, the purpose of this article was to develop and test a model of childhood immunization that includes individual-level characteristics along with contextual characteristics defined at the community and state levels in Nigeria.

\section{Methods}

\section{Study design}

This study used data from the Nigeria Demographic and Health Survey (NDHS) 2013 which is a populationbased cross-sectional survey.

\section{Sampling technique}

The selection of sample was based on clusters and households and this involved a three-stage sampling technique. Nigeria was divided into strata which consist of all the 36 states and the Federal Capital Territory (FCT). Enumeration areas (EAs) were created in every state for easy access to the respondents. In the first stage, 896 clusters were randomly selected. The second stage involved a random selection of one EA from most of the clusters and this resulted in the selection of 372 EAs from the urban areas and 532 from the rural areas. A total of 45 households were selected from each rural and urban area. Altogether, 40,680 households were sampled for the survey; 23,940 in the rural areas and 16,740 in the urban areas. Complete details of the methods used in the NDHS have been published elsewhere [14].

\section{Data collection}

Data were collected through the use of questionnaires that were administered by conducting face-to-face interviews. Information obtained through this process covered socioeconomic characteristics, reproductive history, prenatal and postnatal care, nutrition, immunization and HIV/AIDS. Information on immunization was collected through vaccination cards and mothers' verbal reports. Interviewers asked mothers to present the vaccination cards in order to obtain vaccination dates. In the absence of vaccination cards, such mothers were asked to recall the vaccination administered on to their children. Details of the data collection procedure have been published elsewhere [14].

\section{Outcome variable}

We limited our study to children aged 12-23 months as children at this age are expected to have received all the basic doses of immunization. The outcome variable was calculated using 9 doses of 4 vaccines; Bacillus CalmetteGuérin (BCG) (1 dose), Polio (4 doses), DTP (3 doses) and Measles (1 dose) (see Table 1). The DTP-containing vaccine currently used in Nigeria is a pentavalent vaccine that also includes Haemophilus influenzae type $\mathrm{b}$ and hepatitis B virus antigens. The NDHS applied the WHO recommendations that stipulate that a child is considered fully immunized if he or she received BCG against tuberculosis; 3 doses of vaccine against DTP; at least 3 doses of vaccine against polio and 1 dose of vaccine against measles [14]. The outcome variable was derived from nine variables

Table 1 Routine immunization schedule for children in Nigeria

\begin{tabular}{ll}
\hline At birth & BCG + Polio 0 \\
\hline 6 weeks & DPT $1+$ Polio 1 \\
10 weeks & DPT 2 + Polio 2 \\
14 weeks & DPT 3 + Polio 3 \\
9 months & Measles
\end{tabular}

Source: Federal Ministry of Health, Nigeria [4] 
which represent the doses. Children who received all the nine doses were categorized as fully immunized and those who received less than nine doses were defined as not completely immunized.

\section{Independent variables Individual-level factors}

The following variables were considered in the study: mother's age, education, wealth index, marital status, occupation, sex of child, and birth order. Others include size of child at birth, exposure to mass media, antenatal care and place of delivery. Mother's age was grouped into 15-24, 25-34 and 35+. Education was defined as no education, primary and secondary or higher. Wealth index was originally presented in 5 quintiles by DHS which were derived from the measurements of ownership of household items such as car, radio, television, and dwelling features like toilet facilities, water source and type of roofing/floor. This mode of measurement has been used by the World Bank to categorize households into poverty levels based on principal components analysis $[15,16]$. For easy interpretation, we reclassified the weighted scores into three tertiles (poor, middle and rich). Marital status was grouped into never married and ever married. We categorized maternal occupation as not working and working. Sex of child was defined as male and female. Birth order of children was categorized into 1st -3 rd order, 4th -6 th order and 7 th + order. Size of child at birth was categorized into three; large, average and small. Exposure to mass media refers to the frequency of access to newspaper, radio and television. Those who had access to any of the three outlets (for any number of times in a week) were defined as exposed and others were considered never exposed. Antenatal care was dichotomized as attended for women who paid at least one visit to the clinic during pregnancy and never attended for others. Place of delivery was categorized into health facility for women who delivered at either public or private hospital and home for those who delivered elsewhere.

\section{Community-level factors}

The factors that were considered at the community level included place of residence, difficulty experienced in getting to health facilities, ethnicity diversity index and community socioeconomic status. Place of residence was grouped into urban and rural. Difficulty experienced in getting to health facilities was defined in terms of distance and lack of transportation. This was categorized into having a problem getting to health facilities and not having a problem. Ethnicity diversity index was defined through a formula given as follows
Ethnic diversity index $=1-\sum_{\mathrm{i}=1}^{\mathrm{n}}\left[\frac{x_{i}}{\mathrm{y}}\right]^{2}$

Where: $x_{i}=$ population of ethnic group $\mathrm{i}$ of the area, $\mathrm{y}=$ total population of the area, $n=$ number of ethnic groups in the area.

The index measures the number of ethnic groups in a locality [17]. The formula calculates scores from 0 to approximately 1 and each index is multiplied by 100 to show the diversity. A higher index score implies better ethnic diversity. While a diversity of 0 indicates the community is dominated by one ethnic group, a 100 diversity index implies such a community is populated by various ethnic groups that are equally represented. Socioeconomic status of the community was computed from the socioeconomic characteristics such as education, occupation and wealth of individuals living in the same community. Through a principal components method, the proportion of individuals who are; uneducated, unemployed and poor was calculated. A standardized score of 0 mean and 1 standard deviation was derived from the proportion. The scores were then grouped into three tertiles (least disadvantaged, tertile 2 and most disadvantaged) with the highest score representing a lower socioeconomic status.

\section{State-level factors}

State socioeconomic status was arrived at through socioeconomic characteristics of individuals living within the same state. Such characteristics include education, occupation and wealth. Using a principal components method, proportion of individuals in the same state who are; uneducated, unemployed and poor was calculated. A standardized score of 0 mean and 1 standard deviation was derived from the proportion. The scores were then categorized into three tertiles (least disadvantaged, tertile 2 and most disadvantaged) with the highest score representing a lower socioeconomic status.

\section{Statistical analyses Descriptive analysis}

The descriptive analysis was presented by showing the distributions of independent variables by the outcome variable. The distributions were expressed as numbers and percentages.

\section{Modelling approaches}

We calibrated a three-level binomial logistic regression that had a structure of children with incomplete vaccination or not at level 1 nested within communities at level 2 from a State at level 3. We have applied binomial logistic regression because of the dichotomous nature of the outcome variable. Four models were constructed. The first model is a null model with no independent variables. 
This model was included to decompose the amount of variance that existed between the community and state levels. Second model contained individual-level variables. The third and fourth were expanded to include community- and state-level variables respectively.

\section{Fixed effects (measures of association)}

Fixed effects were presented as odds ratios (OR) with their $95 \%$ credible intervals $(\mathrm{CrI})$.

\section{Random effects (measures of variation)}

The results of random effects comprised an intra-cluster correlation (ICC), a variance partition coefficient (VPC) and median odds ratio (MOR). MOR is the unexplained cluster heterogeneity. Details of the methods applied for computing MOR have been published elsewhere $[18,19]$.

\section{Model Fit and specifications}

We used the Bayesian Deviance Information Criterion (DIC) to assess the goodness of fit of the model. Variance Inflation Factor (VIF) was applied to test for multicollinearity. All the multilevel modelling operations were executed using MLwiN 2.35 [20] calling Stata Statistical Software for windows version 14 [21] using (runmlwin). Markov Chain Monte Carlo (MCMC) estimation was used for the multilevel logistic regression models [22]. $P$ value of $<0.05$ was used to define statistical significance.

\section{Results}

\section{Descriptive statistics}

Table 2 presents the descriptive analysis of the respondents' characteristics. The analysis involved 5,754 children aged 12-23 months (level 1), nested within 896 communities (level 2), from 37 states (level 3) in Nigeria. More than three-quarter of the children $(76.3 \%)$ were not fully immunized. About $83 \%$ of children of young mothers (15-24 years) and 94\% of those whose mothers are illiterate did not receive full immunization. While most children from poor households $(94.6 \%)$ were not fully immunized, about $91 \%$ of children whose mothers never had access to mass media did not receive full immunization. Most children with mothers not attending antenatal clinic (91.6\%) and mothers who delivered at home $(88.5 \%)$ were not fully immunized. The preponderance of children from rural area (85.1\%) and children whose mothers had problem accessing health facility $(71.8 \%)$ did not receive full immunization. About 9 in every 10 children who lived in the most economically disadvantaged communities and states were not fully immunized.

\section{Measures of association}

Table 3 shows the results of the different models considered in the study. After adjusting for the effects of individual-, community- and state level-factors, the probability of a child not receiving full immunization reduced by $45 \%$ for mothers aged 35 and above compared to mothers who are 15-24 years. The odds of a child not being fully immunized reduced as the level of mothers' education increased. Children of mothers with no education $(\mathrm{OR}=2.14 ; 95 \% \mathrm{CrI}=1.59-2.86)$ and primary education $(\mathrm{OR}=1.42 ; \mathrm{CrI}=1.14-1.76)$ are more likely to be incompletely immunized compared with children of women with secondary or higher education. Children from poor households have higher probability of not being fully immunized as the odds reduced by $52 \%$ for children from rich households. Children of higher birth order $(7+)$ and those considered small at birth were $46 \%$ and $32 \%$ more likely to be incompletely immunized respectively. The chances of not being fully immunized reduced for children whose mothers attended antenatal clinic $(\mathrm{OR}=0.49 ; 95 \%$ $\mathrm{CrI}=0.39-0.60)$, delivered in health facility $(\mathrm{OR}=0.62$; $95 \% \mathrm{CrI}=0.51-0.74)$ and lived in urban area $(\mathrm{OR}=0.66$; $95 \% \mathrm{CrI}=0.50-0.82$ ). Children whose mothers had difficulty getting to health facility $(\mathrm{OR}=1.28 ; 95 \% \mathrm{CrI}=$ $1.02-1.57)$ and lived in socioeconomically disadvantaged communities $(\mathrm{OR}=2.93 ; 95 \% \mathrm{CrI}=1.60-4.71)$ and states $(\mathrm{OR}=2.69 ; 955 \mathrm{CrI}=1.37-4.73)$ are more likely to be incompletely immunized.

\section{Measures of variation}

There was a significant variation in the odds of not having children fully immunized across the states $\left(\sigma_{=}^{2} 2.270\right.$; $95 \% \mathrm{CrI}=1.330-3.730)$ and across the communities $\left(\sigma_{=}^{2} 1.578 ; 95 \% \mathrm{CrI}=1.216-1.979\right) \quad$ as indicated in Table 2. The intra-state and intra-community correlation coefficients show that $31.8 \%$ and $53.9 \%$ of the variance in odds of not having a child fully immunized are linked to state- and community-level factors respectively. The MOR underscores the important role community- and state-level factors play in influencing child immunization status. As estimated in model 4, if a mother moved to another state or community that has a higher probability of incomplete child immunization, the likelihood of having her child not fully immunized would increase by 1.54 and 2.39 times respectively.

\section{Discussion}

We found that individual characteristics and community and state factors are important in explaining the variations in incomplete immunization status of children in Nigeria. Children of young women (15-24 years) are more likely to be incompletely immunized when compared with children of older women. This is in agreement with previous studies [23, 24]. This implies that the probability of having a child immunized increases with increasing age of mothers. This scenario may be attributed to the child care experience which the young 
Table 2 Child immunization status at different levels of independent variables

\begin{tabular}{|c|c|c|c|c|}
\hline \multirow[t]{3}{*}{ Variables } & \multicolumn{2}{|c|}{ Immunization status } & \multirow{3}{*}{$\begin{array}{l}\text { Total } \\
\text { N (\%) }\end{array}$} & \multirow[t]{3}{*}{$P$ value } \\
\hline & \multirow{2}{*}{$\begin{array}{l}\text { Fully immunized } \\
\mathrm{N}(\%)\end{array}$} & \multirow{2}{*}{$\begin{array}{l}\text { Not fully immunized } \\
\text { N (\%) }\end{array}$} & & \\
\hline & & & & \\
\hline Individual-level factors & $1,361(23.7)$ & $4,393(76.3)$ & $5,754(100)$ & \\
\hline \multicolumn{5}{|l|}{ Maternal age } \\
\hline $15-24$ & $281(17.4)$ & $1,332(82.6)$ & $1,613(100)$ & \\
\hline $25-34$ & $769(27.1)$ & $2,073(72.9)$ & $2,842(100)$ & \\
\hline $35+$ & $311(23.9)$ & $988(76.1)$ & $1,299(100)$ & $<0.0001$ \\
\hline \multicolumn{5}{|l|}{ Maternal education } \\
\hline No education & $166(6.4)$ & $2,441(93.6)$ & $2,607(100)$ & \\
\hline Primary & $274(24.6)$ & $842(75.4)$ & $1,116(100)$ & \\
\hline Secondary/higher & $921(45.3)$ & $1,110(54.7)$ & $2,031(100)$ & $<0.0001$ \\
\hline \multicolumn{5}{|l|}{ Wealth index } \\
\hline Poor & 103(5.4) & $1,815(94.6)$ & $1,918(100)$ & \\
\hline Middle & $374(19.5)$ & $1,544(80.5)$ & $1,918(100)$ & \\
\hline Rich & $884(64.1)$ & $1,034(53.9)$ & $1,918(100)$ & $<0.0001$ \\
\hline \multicolumn{5}{|l|}{ Marital status } \\
\hline Never married & $54(40.3)$ & $80(59.7)$ & 134(100) & \\
\hline Ever married & $1,307(23.3)$ & $4,313(76.7)$ & $5,620(100)$ & $<0.0001$ \\
\hline \multicolumn{5}{|l|}{ Maternal occupation } \\
\hline Not working & $333(19.0)$ & $1,422(81.0)$ & $1,755(100)$ & \\
\hline Working & $1,028(25.7)$ & $2,971(74.3)$ & $3,999(100)$ & $<0.0001$ \\
\hline \multicolumn{5}{|l|}{ Sex of child } \\
\hline Male & $741(24.6)$ & $2,269(75.4)$ & $3,010(100)$ & \\
\hline Female & $620(22.6)$ & $2,124(77.4)$ & $2,744(100)$ & 0.071 \\
\hline \multicolumn{5}{|l|}{ Birth order } \\
\hline $1 s t-3 r d$ order & $843(28.9)$ & $2,074(71.1)$ & $2,917(100)$ & \\
\hline 4th -6 th order & $392(20.7)$ & $1,499(79.3)$ & $1,891(100)$ & \\
\hline 7th + order & $126(13.3)$ & $820(86.7)$ & $946(100)$ & $<0.0001$ \\
\hline \multicolumn{5}{|l|}{ Size of child at birth } \\
\hline Large & $658(25.8)$ & $1,889(74.2)$ & $2,547(100)$ & \\
\hline Average & $562(24.3)$ & $1,750(75.7)$ & $2,312(100)$ & \\
\hline Small & $141(15.8)$ & $754(84.2)$ & $895(100)$ & $<0.0001$ \\
\hline \multicolumn{5}{|l|}{ Exposure to media } \\
\hline Never exposed & 184(9.3) & $1,791(90.7)$ & $1,975(100)$ & \\
\hline Exposed & $1,177(31.1)$ & $2,602(68.9)$ & $3,779(100)$ & $<0.0001$ \\
\hline \multicolumn{5}{|l|}{ Antenatal care } \\
\hline Never attended & $186(8.4)$ & 2.017(91.6) & $2,203(100)$ & \\
\hline Attended & $1,175(33.1)$ & $2,376(66.9)$ & $3,551(100)$ & $<0.0001$ \\
\hline \multicolumn{5}{|l|}{ Place of delivery } \\
\hline Home & $405(11.5)$ & $3,123(88.5)$ & $3,528(100)$ & \\
\hline Health facility & $956(42.9)$ & $1,270(57.1)$ & $2,226(100)$ & $<0.0001$ \\
\hline \multicolumn{5}{|l|}{ Community-level factors } \\
\hline \multicolumn{5}{|l|}{ Residence } \\
\hline Rural & $572(14.9)$ & $3,260(85.1)$ & $3,832(100)$ & \\
\hline
\end{tabular}


Table 2 Child immunization status at different levels of independent variables (Continued)

\begin{tabular}{llll}
\hline Urban & $789(41.1)$ & $1,133(58.9)$ & $1,922(100)$ \\
Getting to health facility & & & $<0.0001$ \\
Not a problem & $1,115(28.2)$ & $2,843(71.8)$ & $3,958(100)$ \\
A problem & $246(13.7)$ & $1,550(86.3)$ & $1,796(100)$ \\
Ethnicity diversity index, mean(SD) & & & $2.32(2.92)$ \\
Socioeconomic disadvantage & & $1,121(56.8)$ & $1,975(100)$ \\
Tertile 1(least disadvantaged) & $854(43.2)$ & $1,426(76.4)$ & $1,866(100)$ \\
Tertile 2 & $440(23.6)$ & $1,846(96.5)$ & $1,913(100)$ \\
Tertile 3 (most disadvantaged) & $67(3.5)$ & & $<0.0001$ \\
State-level factors & & $1,988(100)$ \\
Socioeconomic disadvantage & & $2,015(100)$ \\
Tertile 1(least disadvantaged) & $772(38.8)$ & $1,520(75.4)$ & $1,751(100)$ \\
Tertile 2 & $495(24.6)$ & $1,657(94.6)$ & $<0.0001$ \\
Tertile 3 (most disadvantaged) & $94(5.4)$ & & $<1.2)$ \\
\hline
\end{tabular}

mothers are yet to acquire. Older mothers have gone through the rigours of caring for sick children with the resultant effects on time and household income. Such mothers would appreciate any initiative designed to prevent the occurrence of childhood illness. Our study shows the role of education in predicting child immunization. As mothers' level of education increased, the probability of having a child not fully immunized reduced such that children of mothers with secondary or higher education have the least likelihood of not being fully immunized when compared with children whose mothers have primary or no education. Education has been reported [25-27] to have a profound effect on mother's health seeking behaviour which includes child immunization. As revealed in similar studies [13, 28], childhood immunization is influenced by the household poverty. The poorer a household becomes, the more the tendency of children from such households to be incompletely immunized. Lack of money results in poor health seeking behaviour and this culminates into double deprivations for the children; they are deprived of nutritious food that could naturally build their immune system and they are also deprived of full immunization that could fortify them against vaccine preventable diseases.

Our findings also show that the use of health service by pregnant mothers contributes to the improvement in the immunization status of children. Children of women that attended antenatal care have lower probability of not being fully immunized compared to children whose mothers did not attend any antenatal care. This is also the view of earlier studies [29-31]. Attending antenatal care puts women in a better position of obtaining adequate information about routine immunization for children. Also, the processes undergone during antenatal care prepare a mother towards having positive inclination to health care utilization not only for themselves but also their children. Consistent with other studies [32, 33], health facility delivery has a significant effect on child immunization. Children of mothers who delivered in health facility are less likely to be incompletely immunized. Health facility delivery affords women the opportunity to have their children immunized at birth and also obtain information on subsequent immunization schedule.

Child characteristics have also been shown to influence immunization. The likelihood of getting a child fully immunized reduced as birth order increased. Children of higher birth order are more likely to be incompletely immunized when compared with children of lower birth order [34, 35]. This could be attributed to mothers' diminished interest in immunization uptake for higher order children. Also, children who were small at birth have higher probability of not receiving full immunization. Findings from previous studies [36] have shown that children in this category are presented for immunization late. This may be as a result of the fragility belief in respect of small children. Parents of such children may consider them too fragile for immunization.

The effects of community- and state- level factors are highlighted in the study. Our findings indicate that the chances of not being fully immunized are higher for children in rural than urban areas $[37,38]$. There are many health facilities in the urban areas and women in such areas have access to them. At the same time, information about child health is accessed through different outlets in urban areas. Mothers' experience in getting to health facility was significantly associated with child immunization. As emphasised in earlier studies $[10,39,40]$, children of mothers who experienced difficulty in reaching health facilities are more 
Table 3 Factors associated with incomplete child immunization identified by multilevel multivariate logistics regression models

\begin{tabular}{|c|c|c|c|c|}
\hline \multirow[t]{2}{*}{ Variable } & Model $1^{a}$ & Model $2^{b}$ & Model $3^{c}$ & Model $4^{d}$ \\
\hline & $\mathrm{aOR}(\mathrm{Crl})$ & $\mathrm{aOR}(\mathrm{Crl})$ & $\mathrm{aOR}(\mathrm{Crl})$ & $\mathrm{aOR}(\mathrm{Crl})$ \\
\hline \multicolumn{5}{|l|}{ Measure of association } \\
\hline \multicolumn{5}{|l|}{ Individual-level factors } \\
\hline \multicolumn{5}{|l|}{ Maternal age } \\
\hline $15-24$ & & 1 (reference) & 1 (reference) & 1 (reference) \\
\hline $25-34$ & & $0.59(0.48-0.72)$ & $0.61(0.50-0.74)$ & $0.63(0,50-0.79)$ \\
\hline $35+$ & & $0.51(0.38-0.67)$ & $0.53(0.40-0.69)$ & $0.55(0.40-0.74)$ \\
\hline \multicolumn{5}{|l|}{ Maternal education } \\
\hline No education & & $2.68(1.99-3.50)$ & $2.12(1.58-2.78)$ & $2.14(1.59-2.86)$ \\
\hline Primary & & $1.413(1.13-1.75)$ & $1.39(1.11-1.72)$ & $1.42(1.14-1.76)$ \\
\hline Secondary/higher & & 1 (reference) & 1 (reference) & 1 (reference) \\
\hline \multicolumn{5}{|l|}{ Wealth index } \\
\hline Poor & & 1 (reference) & 1 (reference) & 1 (reference) \\
\hline Middle & & $0.57(0.43-0.75)$ & $0.72(0.52-0.99)$ & $0.76(0.55-1.03)$ \\
\hline Rich & & $0.29(0.20-0.39)$ & $0.44(0.31-0.64)$ & $0.48(0.32-0.69)$ \\
\hline \multicolumn{5}{|l|}{ Marital status } \\
\hline Never married & & 1 (reference) & 1 (reference) & 1 (reference) \\
\hline Ever married & & $1.37(0.94-2.08)$ & $1.30(0.83-1.89)$ & $1.38(0.77-2.27)$ \\
\hline \multicolumn{5}{|l|}{ Maternal occupation } \\
\hline Not working & & 1 (reference) & 1 (reference) & 1 (reference) \\
\hline Working & & $0.93(0.77-1.14)$ & $1.02(0.83-1.22)$ & $1.02(0.83-1.23)$ \\
\hline \multicolumn{5}{|l|}{ Sex of child } \\
\hline Male (vs female) & & $0.93(0.78-1.09)$ & $0.92(0.78-1.08)$ & $0.92(0.78-1.09)$ \\
\hline \multicolumn{5}{|l|}{ Birth order } \\
\hline 1st -3rd order & & 1 (reference) & 1 (reference) & 1 (reference) \\
\hline 4th -6th order & & $1.51(1.24-1.85)$ & $1.56(1.27-1.90)$ & $1.53(1.24-1.86)$ \\
\hline 7th + order & & $1.49(1.07-2.03)$ & $1.50(1.06-2.07)$ & $1.46(1.02-2.02)$ \\
\hline \multicolumn{5}{|l|}{ Size of child at birth } \\
\hline Large & & 1 (reference) & 1 (reference) & 1 (reference) \\
\hline Average & & $1.11(0.92-1.32)$ & $1.10(0.93-1.29)$ & $1.13(0.94-1.35)$ \\
\hline Small & & $1.30(0.97-1.68)$ & $1.28(0.98-1.64)$ & $1.32(1.002-1.72)$ \\
\hline \multicolumn{5}{|l|}{ Exposure to media } \\
\hline Never exposed & & 1 (reference) & 1 (reference) & 1 (reference) \\
\hline Exposed & & $0.92(0.75-1.14)$ & $0.99(0.79-1.24)$ & $1.03(0.79-1.31)$ \\
\hline \multicolumn{5}{|l|}{ Antenatal care } \\
\hline Never attended & & 1 (reference) & 1 (reference) & 1 (reference) \\
\hline Attended & & $0.45(0.37-0.54)$ & $0.48(0.38-0.58)$ & $0.49(0.39-0.60)$ \\
\hline \multicolumn{5}{|l|}{ Place of delivery } \\
\hline Home & & 1 (reference) & 1 (reference) & 1 (reference) \\
\hline Health facility & & $0.57(0.46-0.69)$ & $0.61(0.49-0.75)$ & $0.62(0.51-0.74)$ \\
\hline \multicolumn{5}{|l|}{ Community-level factors } \\
\hline \multicolumn{5}{|l|}{ Residence } \\
\hline Urban(vs Rural) & & & $0.67(0.52-0.84)$ & $0.66(0.50-0.82)$ \\
\hline
\end{tabular}

Getting to health facility 
Table 3 Factors associated with incomplete child immunization identified by multilevel multivariate logistics regression models (Continued)

\begin{tabular}{|c|c|c|c|c|}
\hline Not a problem & & & 1 (reference) & 1 (reference) \\
\hline A problem & & & $1.25(0.99-1.54)$ & $1.28(1.02-1.57)$ \\
\hline Ethnicity diversity index & & & $0.99(0.95-1.03)$ & $0.99(0.95-1.03)$ \\
\hline \multicolumn{5}{|l|}{ Socioeconomic disadvantage } \\
\hline Tertile 1 (least disadvantaged) & & & 1 (reference) & 1 (reference) \\
\hline Tertile 2 & & & $1.53(1.17-2.02)$ & 1.44(1.09-1.88) \\
\hline Tertile 3 (most disadvantaged) & & & $3.69(2.09-6.50)$ & $2.93(1.60-4.71)$ \\
\hline \multicolumn{5}{|l|}{ State-level factors } \\
\hline \multicolumn{5}{|l|}{ Socioeconomic disadvantage } \\
\hline Tertile 1 (least disadvantaged) & & & & 1 (reference) \\
\hline Tertile 2 & & & & $0.88(0.57-1.28)$ \\
\hline Tertile 3 (most disadvantaged) & & & & $2.69(1.37-4.73)$ \\
\hline \multicolumn{5}{|l|}{ Measures of variation } \\
\hline \multicolumn{5}{|l|}{ State level } \\
\hline Variance (SE) & $2.270(1.330-3.730)$ & $0.388(0.179-0.740)$ & $0.282(0.113-0.567)$ & $0.205(0.081-0.412)$ \\
\hline Explained variation (\%) & Reference & 82.9 & 87.6 & 91.0 \\
\hline ICC (\%) & 31.80 & 8.76 & 6.36 & 4.72 \\
\hline MOR & 4.18 & 1.81 & 1.66 & 1.54 \\
\hline \multicolumn{5}{|l|}{ Community level } \\
\hline Variance (SE) & $1.578(1.216-1.979)$ & $0.752(0.512-1.013)$ & 0.863(0.610-1.144) & $0.838(0.598-1.104)$ \\
\hline Explained variation (\%) & Reference & 52.3 & 45.3 & 46.9 \\
\hline ICC (\%) & 53.91 & 25.74 & 25.82 & 24.06 \\
\hline MOR & 3.30 & 2.28 & 2.42 & 2.39 \\
\hline \multicolumn{5}{|l|}{ Model fit statistics } \\
\hline Bayesian DIC & 4791 & 4581 & 4542 & 4540 \\
\hline
\end{tabular}

Abbreviations: SE standard error, DIC deviation information criterion, Crl credible interval, ICC intra-cluster correlation, MOR median odds ratio

${ }^{a}$ Model 1 is the empty model, a baseline model with no independent variable

${ }^{b}$ Model 2 is adjusted for age, education, wealth status of family, marital status, occupation, sex of child, birth order, size of child at birth, exposure to media, antenatal care and place of delivery

${ }^{\mathrm{c}}$ Model 3 is additionally adjusted for residency, getting to health facility, ethnicity diversity index and community socioeconomic factors

${ }^{\mathrm{d}}$ Model 4 is additionally adjusted for state-level socioeconomic factors

likely to be incompletely immunized. Difficulty in getting to health facilities serves as a major barrier to child immunization uptake. This is typical of those living in remote areas. The likelihood of not being fully immunized increased for children whose mothers live in socioeconomically disadvantaged communities and states. This confirms the findings of previous studies [12, 41] which revealed that socioeconomic nature of the communities influences the health seeking behaviour of individuals.

\section{Policy implications}

Nigeria is one of the 10 countries in the world where most of the incompletely immunized children live despite the huge investments in immunization programme by governmental and non-governmental organizations. There is a disparity in the rate of immunization incompleteness between the north and south of the country with the former having a higher proportion. This disparity could be explained by the factors that operate at individual, community and state levels. Low level of educational attainment, high level of poverty, poor antenatal care attendance and hospital delivery, higher population of rural inhabitants including poor socioeconomic status are more pronounced in the northern region. Evidence from other studies also emphasized that child immunization incompleteness in the north contributes significantly to the overall low immunization uptake in Nigeria. Some of the factors attributed to this include misconception about immunization (a situation where it is believed that once a child receives polio vaccine, such child has been immunized against all childhood diseases), rejection of routine immunization (this is linked to the fear on the part of parents and care givers that 
vaccines are harmful to the child) and political problems (this relates to lack of commitment from the government about the immunization policy and too much centralization of the immunization programme) [42]. In view of this, our study suggests some policy measures for addressing this situation. Health service providers in conjunction with community leaders need to organize awareness programmes on regular basis at the community level. Such programmes should focus on emphasizing the importance of health service utilization for mothers and children. In addition, issues relating to misconception about vaccines and unwillingness of mothers to present children who were small at birth and those of higher birth order for immunization should be adequately discussed. While government at federal level should address the problem of over-centralization of the immunization policy, government at both state and federal levels should provide funds for the establishment of mobile clinics in order to ensure that immunization services are available to children whose mothers reside in remote areas. This would also eliminate the problem associated with lack of money for transportation. Adult education programme should be resuscitated in Nigeria to give illiterate mothers the opportunity of being educated. Government at all levels need to commit more resources to improving people's socioeconomic status through the provision of employment opportunities, interest-free loans for small and medium scale enterprises and unemployment benefits. This would go a long way in reducing inequalities in the country.

\section{Study strengths and weaknesses}

Some limitations of the present study should be noted. First, our findings depend on the quality of DHS data. DHS is the largest program for the collection of quantitative data on population and health from households in the developing countries and is generally considered as one of the most reliable sources of maternal and child health data. Furthermore, the participants' survey is cross-sectional, so causal relationships between variables of interest cannot be assessed. In addition, because the data were self-reported, it is possible that the responses were affected by recall and social desirability bias.

However, the survey is population-based which covered all the states and regions in the country. This, therefore, allows the results from this study to be generalized to the studied population and other countries in sub-Saharan Africa with similar settings.

\section{Conclusions}

This study has shown that individual-, community- and state-level factors significantly influence child immunization incompleteness in Nigeria. Interventions to improve child immunization uptake should take into consideration the individual, community and state level characteristics. It will be of great benefit if all these factors are properly considered during planning, formulation and implementation of policies by governmental and non-governmental organizations that will improve childhood immunization coverage in Nigeria and other countries.

\section{Abbreviations}

aOR: Adjusted odds ratio; Crl: Credible interval; DIC: Deviation information criterion; ICC: Intra-Cluster Correlation; MOR: Median odds ratio; NDHS: Nigeria demographic and health survey; SE: Standard error

\section{Acknowledgements \\ The data used in this study were made available through DHS Archive. The data were originally collected by the ICF Macro, Calverton USA. Neither the original collectors of the data nor the Data Archive bear any responsibility for the analyses or interpretations presented in this project. \\ Funding \\ This study was supported by the Consortium for Advanced Research Training in Africa (CARTA) through the fund for the Postdoctoral Fellowship of the first author at University of Warwick Medical School. CARTA is jointly led by the African Population and Health Research Center and the University of the Witwatersrand and funded by the Wellcome Trust (UK) (Grant No: 087547/Z/08/Z), the Carnegie Corporation of New York (Grant No: B 8606.R02), Sida (Grant No: 54100029). The statements made and views expressed are solely the responsibility of the authors.}

\section{Availability of data and materials}

This study was based on analyses of secondary data set from the DHS program which gave us the permission for its use. The survey was approved by Institutional Review Board (IRB) of ICF Macro International in the United States and the National Ethics Committee in the Federal Ministry of Health of Nigeria. All participants in the survey gave their consent to participate. The data set (Children's recode) supporting the conclusions of this article is available from the DHS Program archive at http://dhsprogram.com/data/ dataset/Nigeria_Standard-DHS_2013.cfm?flag=0.

\section{Authors' contributions}

STA conceived the original idea for the study, was involved in the design of the study, data acquisition, statistical analyses, interpretation of data, drafting and revision of the manuscript and approved the final manuscript as submitted. OAU contributed to the conception and design of the study, data acquisition, statistical analyses, interpretation of data, drafting and revision of the manuscript and approved the final manuscript as submitted. VTA contributed to the conception and design of the study, data acquisition, statistical analyses, interpretation of data, drafting and revision of the manuscript and approved the final manuscript as submitted. CSW contributed to the conception and design of the study, data acquisition, interpretation of data, revision of the manuscript and approved the final manuscript as submitted. All authors approved the final manuscript as submitted and agree to be accountable for all aspects of the work.

\section{Competing interest}

The authors declare that they have no competing interest.

Consent for publication

Not Applicable.

Ethics approval and consent to participate Not Applicable.

What is already known about this subject?

Most studies on the determinants of incomplete child immunization had concentrated on individual factors leaving out the community- and statelevel factors 


\section{What this study adds?}

- This study examined the association between incomplete child immunization and individual-, community- and state-level factors in one analytical frame work

- The study showed that individual-, community- and state-level factors are significantly associated with incomplete child immunization

\section{Author details}

${ }^{1}$ Warwick-Centre for Applied Health Research and Delivery (WCAHRD), Division of Health Sciences, University of Warwick Medical School, Coventry, UK. '2Department of Demography and Social Statistics, Obafemi Awolowo University, Ile-Ife, Nigeria. ${ }^{3}$ Centre for Evidence-based Health Care, Faculty of Medicine and Health Sciences, Stellenbosch University, Cape Town, South Africa. ${ }^{4}$ NIHR Collaboration for Leadership in Applied Health Research and Care, West Midlands (CLAHRC WM), University of Warwick Medical School, Coventry, UK. ${ }^{5}$ South African Cochrane Centre, South African Medical Research Council, Cape Town, South Africa.

\section{Received: 29 June 2016 Accepted: 15 February 2017}

Published online: 08 March 2017

\section{References}

1. Levels and Trends in Child Mortality. Report 2015. Estimates Developed by UN Inter-Agency Group for Child Mortality Estimation [http://www. childmortality.org/files_v20/download/IGME\%20report\%202015\%20child\%20 mortality\%20final.pdf] Accessed 12 mar 2016

2. Child Morbidity and Mortality. Child Mortality is Common, and Largely Preventable [http://www.jhsph.edu/research/centers-and-institutes/ivac/ resources/info-child-morbidity-mortality.html] Accessed 7 Mar 2016

3. Immunization, Vaccines and Biological: Global Immunization Vision and Strategy [www.who.int/immunization/givs/en/] Accessed 2 Feb 2016

4. Federal Ministry of Health Nigeria. Comprehensive EPI Multi-Year Plan 2011 2015. National Primary Health Care Development Agency. 2011.

5. Global Vaccine Action Plan 2011-2020 [http//www who.int/immunization/ global_vaccine_action_plan/en/] Accessed 3 Mar 2016

6. Nigeria Demographic and Health Survey 1990 [http://www.dhsprogram. com/pubs/pdf/FR27/FR27.pdf] Accessed 2 Mar 2016

7. Nigeria Demographic and Health Survey 2003 [http://www.dhsprogram. com/pubs/pdf/FR148/FR148.pdf] Accessed 2 Mar 2016

8. Nigeria Demographic and Health Survey 2008 [http://www.dhsprogram. com/pubs/pdf/FR222/FR222.pdf] Accessed 5 Mar 2016

9. Brown VB, Oluwatosin OA. Socio-demographic Factors Associated with Childhood Immunization Uptake in Akinyele Local Governmnet Area of Oyo State, Nigeria. Afr J Med Sci. 2012;41(2):161-7.

10. Chidiebere ODI, Uchenna E, Kenechi OS. Maternal Sociodemographic Factors that Influence Full Child Immunization Uptake in Nigeria. South African Journal of Child Health. 2014:8(4):138-42.

11. Tagbo BN, Eke CB, Omolowo Bl, Onwuasigwe CN, Onyeka EB, Mildred UO Vaccination Coverage and its Determinants in Children Aged 11-23 Months in an Urban District of Nigeria. World Journal of Vaccines. 2014;4:175-83.

12. Antai D. Inequitable Childhood Immunization Uptake in Nigeria: A Multilevel Analysis of Individual and Contextual Determinants. BMC Infect Dis. 2009;9(181)

13. An DTM, Lee J-K, Minh HV, Trang NTH, Huong NTT, Nam Y-S, Dung DV. Timely Immunization Completion Among Children in Vietnam From 2000 to. A Multilevel Analysis of Individual and Contextual Factors. Glob Health Action. 2011;2016:9(29189). doi:10.3402/gha.v9.29189.

14. Nigeria Demographic and Health Survey 2013 [http://www.dhsprogram. com/pubs/pdf/FR293/FR293.pdf] Accessed 4 Mar 2016

15. Montgomery MR, Gragnolati M, Burke KA, Paredes E. Measuring Living Standards with Proxy Variables. Demography. 2000;37(2):155-74.

16. Filmer D, Pritchett LH. Estimating Wealth Effects without Expenditure Data-or Tears: An Application to Educational Enrollments in States of India. Demography. 2001;38(1):115-32.

17. Vyas S, Kumaranayake L. Constructing Socio-economic Status Indices: How to Use Principal Components Analysis. Health Policy Plan. 2006; 21(6):459-68.

18. Larsen K, Merlo J. Appropriate Assessment of Neighbourhood Effects on Individual Health: Integrating Random and Fixed Effects in Multilevel Logistic Regression. Am J Epidemiol. 2005;161(1):81-8.
19. Larsen K, Petersen JH, Budtz-Jorgensen E, Endahl L. Interpreting Parameters in the Logistic Regression Model with Random and Fixed Effects. Biometrics. 2000;56(3):909-14

20. Rasbash J, Steele F, Browne W, Prosser B. A User's Guide to MLwiN. Version 2.35. Bristol: Centre for Multilevel Modelling, University of Bristol; 2015.

21. StataCorp. Stata Statistics Software. StataCorp: College Station; 2015.

22. Goldstein H. Multilevel Statistical Models. London: Hodder Arnold; 2003.

23. Negussie A, Kassahun W, Assegid S, Hagan AK. Factors Associated with Incomplete Childhood Immunization in Arbegora District, Southern Ethiopia: A Case-control Study. BMC Public Health. 2015;16(27). doi:10.1186/ s12889-015-26-1.

24. Mutua MK, Kimani-Murage E, Ettarh RR. Childhood Vaccination in Informal Urban Settlements in Nairobi, Kenya: Who Gets Vaccinated? BMC Public Health. 2011;11(16). doi:10.1186/1471-2458-11-6.

25. Shuaib F, Kimbrough D, Roofe M, McGwin Jr G. Factors Associated with Incomplete Childhood Immunization among Residents of St. Mary Parish of Jamaica. West Indian Med J. 2010;59(5):549-54.

26. Abuya BA, Onsomu EO, Kimani JK, Moore D. Influence of Maternal Education on Child Immunization and Stunting in Kenya. Matern Child Health J. 2011:15(8):1389-99.

27. Bbaale E. Factors Influencing Immunization in Uganda. J Health Popul Nutr. 2013:31(1):118-29.

28. Tesfaye F, Tamiso A, Birham Y, Tadele T. Predictors of Immunization Defaulting among Children Age 12-23 Months in Hawassa Zuria District of Southern Ethiopia. International Journal of Public Health Science. 2014;3(3):185-93.

29. Phathammavong O, Ali M, Souksavat S, Chounramany K, Kuroiwa C. Antenatal care among ethnic populations in Louang Namtha Province, Lao PDR. Southeast Asian J Trop Med Public Health. 2010;41(3):705-16.

30. Etana B, Deressa W. Factors Associated with Complete Immunization Coverage in Children Age 12-23 Months in Ambo Woreda, Central Ethiopia. BMC Public Health. 2012:12(566). doi:10.1186/1471-2458-12-566.

31. Sullivan MC, Tegegn A, Tessema F, Galea S, Hadley C. Minding Immunization Gap: Family Characteristics Associated with Completion Rates in Rural Ethiopia. J Community Health. 2010;35(1):53-9.

32. Shrivastwa N, Gillespie BW, Kolenic GE, Lepkowski JM, Boulton ML. Predictors of Vaccination in India for Children Aged 12-36 Months. Am J Prev Med. 2015; 49(6):S434-44.

33. Nankabirwa V, Tylleskar T, Tumwine JK, Sommerfelt H, Group P-eS. Maternal Education is Associated with Vaccination Status of Infants Less than 6 Months in Eastern Uganda: A Cohort Study. BMC Pediatr. 2010;10(92). doi: 10.1186/1471-2431-10-92.

34. Barata RB, Ribeiro MC, De Moraes JC, Flannery B. Socioeconomic Inequalities and Vaccination Coverage: Results of an Immunization Coverage Survey in 27 Brazilian Capitals, 2007-2008. J Epidemiol Community Health. 2012;66:934-41.

35. Mathew JL. Inequity in Childhood Immunization in India: A Systematic Review. Indian Pediatr. 2012:49:203-23.

36. Mutua MK, Ochako R, Ettarh R, Ravn H, Echoka E, Nwaniki P. Effects of Low Birth Weight on Time to BCG Vaccination in an Urban Poor Settlement in Nairobi, Kenya: An Observational Cohort Study. BMC Pediatr. 2015;15(45). doi:10.1186/s12887-015-0360-5

37. Singh PK. Trends in Child Immunization Across Geographical Regions in India: Focus on Urban-rural and Gender Differentials. PLoS One. 2013; 8(9):e73102

38. Owais A, Hanif B, Siddiqui AR, Agha A, Zaidi AKM. Does Improving Maternal Knowledge of Vaccines Impact Infant Immunization Rates? A CommunityBased Randomized-Controlled Trial in Karachi, Pakistan. BMC Public Health. 2011:11(239). doi:10.1186/1471-2458-11-239.

39. Abdulraheem IS, Onajole AT, Jimoh AAG, Oladipo AR. Reasons for Incomplete Vaccination and Factors for Missed Opportunities among Rural Nigerian Children. Journal of Public Health and Epidemiology. 2011;3(4):194-203.

40. Okwaraji YB, Mulholland K, Schellenberg J, Andarge G, Admassu M, Edmond KM. The Association Between Travel Time to Health Facilities and Childhood Vaccine Coverage in Rural Ethiopia: A Community Based Cross Sectional Study. BMC Public Health. 2012;12(476). doi:10.1186/1471-2458-12-476.

41. Wiysonge CS, Uthman OA, Ndume PM, Hussey GD. Individual and Contextual Factors Asociated with Low Childhood Immunization Coverage in sub-Saharan Africa: A Multilevel Analysis. PLoS One. 2012;7(5):e37905.

42. Ophori EA, Tula YM, Azih A, Okojie R, Ikpo PE. Current Trends of Immunization in Nigeria: Prospect and Challenges. Tropical Medicine and Health. 2014:42(2):67-75. 